\title{
Esophageal duplication cyst
}

INSERM

\section{Source}

INSERM. (1999). Orphanet: an online rare disease and orphan drug data base.

Esophageal duplication cyst. ORPHA:100047

Esophageal duplication cyst is a rare, congenital, non-syndromic esophageal

malformation, most frequently located in the distal esophagus and usually diagnosed in

childhood, characterized by tubular or spherical cystic masses that have a double layer of surrounding smooth muscle lined with squamous or enteric epithelium, are continuous or contiguous to the esophagus and may, or may not, communicate with the esophageal lumen. Patients are frequently asymptomatic, or could present with a wide range of symptoms including respiratory distress, failure to thrive, dysphagia, epigastric discomfort, vomiting, stridor, non-productive cough, and chest pain. Other more rare symptoms, such as cardiac arrhythmia, thoracic back pain, cystic hemorrgage and ulceration, and mediastinitis, have also been reported. 